\title{
Níveis de grão de capim-pé-de-galinha (Eleusine coracana) em dietas para ovinos: consumo e digestibilidade ${ }^{1}$
}

\section{José Walter dos Santos ${ }^{2}$, Luciano da Silva Cabral ${ }^{3}$, Joanis Tilemahos Zervoudakis $^{3}$, Alexandre Lima de Souza ${ }^{4}$, Joadil Gonçalves de Abreu ${ }^{3}$, Robson Reverditto ${ }^{5}$, Gisele Abadia de Campos Pereira ${ }^{6}$}

\author{
${ }^{1}$ Financiado pela FAPEMAT e pelo CNPq. \\ 2 Escola Agrotécnica da São Gabriel da Cachoeira - AM. \\ ${ }^{3}$ Faculdade de Agronomia e Medicina Veterinária - UFMT, Av. Fernando Corrêa da Costa, s/n, Coxipó, Cuiabá - MT, CEP: 78060-900. \\ 4 Instituto de Ciências Exatas e Naturais, Campus Universitário de Rondonópolis - UFMT, Rondonópolis - MT. \\ ${ }^{5}$ Programa de Pós-Graduação em Ciência Animal da UFMT. \\ ${ }^{6}$ Curso de Agronomia da FAMEVIUFMT.
}

RESUMO - Objetivou-se avaliar em ovinos o consumo e a digestibilidade de nutrientes de dietas contendo grão de capimpé-de-galinha (Eleusine coracana). Foram utilizados 20 ovinos com peso vivo inicial de 18,90 kg, em delineamento inteiramente casualizado, com cinco tratamentos e quatro repetições. Os animais foram alimentados com dietas isoprotéicas formuladas com $50 \%$ de volumoso e $50 \%$ de concentrado contendo $0 ; 16,0 ; 32,5 ; 48,0$ ou $67,0 \%$ de grão de capim-pé-de-galinha em substituição ao fubá de milho. Utilizou-se a fibra indigestível em detergente neutro (FDNi) como indicador para estimativa da excreção fecal. Os níveis de grão de pé-de-galinha não influenciaram os consumos de MS, NDT e FDN. Os valores médios de consumo de matéria seca foram de $1,2 \mathrm{~kg} /$ animal/dia e 3,2\% do peso vivo. O coeficiente de digestibilidade da matéria seca (CDMS) e o NDT reduziram linearmente em 0,1425 e $0,1612 \%$, respectivamente, a cada $1 \%$ de grão de capim-pé-de-galinha no concentrado, o que está relacionado aos maiores teores de FDN e FDNi desse alimento. Os coeficientes de digestibilidade de MO e FDN apresentaram valores máximos de 57,64 e 53,60\% nos níveis de 42,36 e 39,56\% de grão de capim-pé-de-galinha no concentrado. Os valores médios de digestibilidade aparente de PB e EE foram 56,90 e 66,86\%, respectivamente. A substituição do fubá de milho por grão do capim pé-de-galinha na dieta de ovinos não influenciou o consumo de matéria seca dos nutrientes, mas reduziu o coeficiente de digestibilidade da matéria seca, da matéria orgânica, dos carboidratos totais e os nutrientes digestíveis totais, logo, esse ingrediente pode substituir até $50 \%$ do fubá de milho no concentrado para ovinos.

Palavras-chave: confinamento, cordeiros, ingredientes alternativos

\section{Finger millet grain levels in sheep diets: intake and digestibility}

\begin{abstract}
The objective was to evaluate in sheep the intake and apparent digestibility of nutrients diets containing finger millet grain (Eleusine coracana). Twenty lambs were used with average initial $18.90 \mathrm{~kg} \mathrm{BW}$, in a completely randomized design, with five diets and four replications. The animals were fed isoprotein diets formulated with $0.0,16.0,32.5,48.0$ e $67.0 \%$ of finger millet grain in substitution of corn meal, with 50:50 forage to concentrate ratio (\%DM). The levels of finger millet grain did not affect the intake of DM, TDN and NDF. Dry matter intake was $1.2 \mathrm{~kg} / \mathrm{anim} / \mathrm{d}$ and $3.2 \%$ of BW. The coefficient of apparent digestibility of DM and NDT linearly decreased in 0.1425 and $0.1612 \%$, respectively, for each $1 \%$ of finger millet grain in the concentrate, which is related to higher levels of NDF and NDFi in this feed. The digestibility coefficients OM and NDF showed maximum values of 57.64 and $53.60 \%$ in the levels of 42.36 and $39.56 \%$ of finger millet grain in the concentrate Apparent digestibility of $\mathrm{CP}$ and EE were 56.90 and $66.86 \%$ respectively. The replacement of corn meal per finger millet grain in the diet of sheep does not affected dry matter intake of nutrients, but reduced the digestibility of DM, OM, total carbohydrates and TDN. Then, this ingredient could replace up to $50 \%$ of corn meal in the concentrate for sheep.
\end{abstract}

Key Words: alternative ingredients, feedlot, lambs

\section{Introdução}

Existem no Brasil aproximadamente 17 milhões de ovinos, dos quais aproximadamente $45 \%$ encontram-se na Região Nordeste. Entretanto, outras regiões, como a
Sudeste e a Centro Oeste, têm apresentado elevado crescimento da atividade. No estado de Mato Grosso, o crescimento do rebanho foi de $37 \%$ ao ano nos últimos anos (Santos et al., 2004). Possuidor de formidável fronteira agrícola, de clima bastante definido (uma estação de chuvas 
de 7 meses e uma de seca de 5 meses) e elevada disponibilidade de grãos e subprodutos, esse estado apresenta nas mais diversas regiões elevado potencial de produção de ovinos.

Apesar da predominância dos sistemas de produção a pasto no estado, a criação dos animais nesse sistema é prejudicada pela sazonalidade na produção forrageira, que inviabiliza o abate de animais precoces, e pela verminose, principal enfermidade que acomete a espécie ovina. Assim, o confinamento consiste em importante estratégia de produção de carne em curto de espaço de tempo por meio da utilização de animais precoces.

Considerando que o fubá de milho é o principal componente das dietas desses animais em confinamento, buscam-se alimentos alternativos que possam substituir o milho, de modo a reduzir os custos com alimentação e permitir aos animais a manutenção de elevadas taxas de crescimento.

O grão de capim-pé-de-galinha (Eleusine coracana) é obtido da cultura desse capim, o qual tem sido empregado em muitas propriedades no estado de Mato Grosso em rotação com a cultura da soja no sistema de plantio direto. Desta forma, tem havido interesse no uso desse grão em dietas para ruminantes com o objetivo de reduzir os custos de produção decorrentes do elevado preço do fubá de milho. Na região, o grão desse capim custa, em média, metade do preço do milho, portanto, sua utilização na alimentação animal poderia representar importante redução dos custos de produção.

Considerando que o desempenho produtivo dos animais depende do consumo, da digestibilidade e do metabolismo dos nutrientes dietéticos (Crampton et al., 1960; Reid, 1961), torna-se necessária a avaliação desse ingrediente por meio de ensaios de digestibilidade para identificar seus efeitos sobre o consumo e a digestibilidade dos nutrientes da dieta e sobre o desempenho animal.

Assim, objetivou-se avaliar os efeitos da inclusão de grão de capim-pé-de-galinha em substituição ao fubá de milho em dietas para ovinos em confinamento sobre o consumo e a digestibilidade dos nutrientes dietéticos.

\section{Material e Métodos}

O experimento foi conduzido no Setor de Ovinocultura da Fazenda Experimental da Universidade Federal de Mato Grosso (UFMT), localizada no município de Santo Antônio do Leverger - Mato Grosso, nas coordenadas de $15^{\circ} 47^{\prime} 05^{\prime \prime}$ Sul e $56^{\circ} 04^{\prime}$ Oeste, a $140 \mathrm{~m}$ de altitude, no período de 13 de setembro a 5 de outubro de 2005.

Foram utilizados 20 animais da raça Santa Inês, machos não-castrados, com 120 dias de idade e peso vivo médio inicial em jejum (PVIJ) de 18,90 kg, distribuídos em delineamento inteiramente casualizado com cinco tratamentos (níveis do grão do capim pé-de-galinha) e quatro repetições. Inicialmente, os animais foram casqueados, vacinados contra clostridiose, pesados, identificados e tratados contra endoparasitos. Os animais foram mantidos em baias próprias para estudos de metabolismo, dotadas de bebedouro e comedouro.

O ensaio teve duração de 21 dias: 14 dias de adaptação dos animais às dietas e 7 de monitoramento do consumo e coleta de amostras de alimentos, sobras e fezes para avaliação da digestibilidade total.

As dietas, compostas de $50 \%$ de volumoso (25\% canade-açúcar in natura picada e $25 \%$ de silagem de milho) e $50 \%$ de concentrado, foram formuladas com $0,25,50,75$ ou $100 \%$ de grão de capim-pé-de-galinha em substituição ao fubá de milho do concentrado, correspondendo a $0 ; 16,0$; 32,$5 ; 48,0$ ou $67,0 \%$ de grão do capim pé-de-galinha no concentrado (Tabela 1). Os concentrados, formulados para serem isoprotéicos (22\% de proteína bruta - PB), foram compostos de fubá de milho e farelo de soja, uréia, mistura mineral (Navifos ${ }^{\circledR}$ ) e grão de capim-pé-de-galinha, de modo a resultar em $15 \%$ de PB na dieta, de acordo com o NRC (1985).

A dieta era fornecida na forma de ração completa, duas vezes ao dia: a primeira às $7 \mathrm{~h} 30$ e a segunda às $15 \mathrm{~h} 30$. Diariamente, durante todo o período experimental, antes do primeiro trato, as sobras de alimentos do dia anterior eram recolhidas e pesadas para controle da quantidade fornecida, de modo que o percentual se mantivesse próximo a $10 \%$ do fornecimento, com base na matéria natural. Nos últimos sete dias do ensaio, a oferta e as sobras foram monitoradas para avaliação do consumo, calculado como a diferença entre a quantidade ofertada e as sobras.

A coleta de amostras de fezes para determinação da digestibilidade dos nutrientes foi realizada diretamente do

Tabela 1 - Composição percentual dos concentrados de acordo com os níveis de substituição do fubá de milho pelo grão de capim-pé-de-galinha (\% da matéria seca)

\begin{tabular}{lccccc}
\hline & \multicolumn{5}{c}{ Nível de grão e capim-pé-de-galinha } \\
& \multicolumn{5}{c}{ no concentrado $(\%)$} \\
\cline { 2 - 6 } Ingrediente & 0 & 16,0 & 32,5 & 48,0 & 67,0 \\
\hline Fubá de milho & 64,0 & 49,0 & 32,5 & 19,0 & 0,0 \\
$\begin{array}{l}\text { Farelo de soja } \\
\text { Grão do capim- }\end{array}$ & 30,0 & 29,0 & 29,0 & 27,0 & 27,0 \\
pé-de-galinha & 0,0 & 16,0 & 32,5 & 48,0 & 67,0 \\
$\begin{array}{l}\text { Mistura mineral } \\
\text { (Navifos }{ }^{\circledR} \text { ) }\end{array}$ & 5,0 & 5,0 & 5,0 & 5,0 & 5,0 \\
Uréia & 1,0 & 1,0 & 1,0 & 1,0 & 1,0 \\
\hline
\end{tabular}


Tabela 2 - Composição químico-bromatológica dos ingredientes e das dietas

\begin{tabular}{|c|c|c|c|c|c|c|c|c|}
\hline Ingrediente & \multicolumn{8}{|c|}{ Composição química ( $\%$ da matéria seca) } \\
\hline Fubá de milho & 93,76 & 7,42 & 3,90 & 1,50 & 87,19 & 14,51 & 99,97 & 6,67 \\
\hline Grão de capim-pé-de-galinha & 93,88 & 9,31 & 0,70 & 3,29 & 86,70 & 22,24 & 99,94 & 15,50 \\
\hline Silagem de milho & 26,03 & 8,28 & 1,96 & 6,75 & 83,01 & 59,67 & 99,97 & 24,63 \\
\hline Cana-de-açúcar & 27,46 & 4,63 & 2,56 & 3,18 & 88,63 & 41,98 & 99,94 & 19,72 \\
\hline
\end{tabular}

MS - matéria seca, PB - proteína bruta, EE - extrato etéreo, CT - carboidrato total, FDN - fibra insolúvel em detergente neutro, MO - matéria mineral FDNi - fibra insolúvel em detergente neutro indigestível.

reto dos animais, durante os sete dias finais do experimento, em intervalos de 26 horas.

As amostras dos ingredientes volumosos, das rações, das sobras e das fezes foram pesadas, identificadas, embaladas em sacos plásticos e acondicionadas em freezer até o término do experimento para posteriores análises. Após o experimento, as amostras foram encaminhadas ao Laboratório de Nutrição Animal a FAMEV/UFMT, onde foram descongeladas e homogeneizadas para obtenção de amostras compostas por animal. As amostras dos volumosos e das sobras e fezes foram pré-secas em estufa de ventilação forçada a $60 \pm 5^{\circ} \mathrm{C}$, por 72 horas. Em seguida, foram trituradas em moinho tipo Willey utilizando-se peneiras com porosidade de $1 \mathrm{~mm}$ e submetidas a análises para determinação dos teores de matéria seca (MS), proteína bruta (PB), extrato etéreo (EE) e matéria mineral (MM), de acordo com metodologia descrita por Silva \& Queiroz (2004), e fibra insolúvel em detergente neutro (FDN), conforme metodologia de Van Soest et al. (1991). Os carboidratos totais (CT) foram obtidos pela fórmula $\mathrm{CT}=100-(\% \mathrm{~PB}+\% \mathrm{MM}+\% \mathrm{EE})$, conforme descrito por Sniffen et al. (1992).

Para determinação dos teores de FDNi, utilizada como indicador interno para estimação da excreção fecal, as amostras dos volumosos, dos concentrados e das sobras e fezes foram acondicionadas em sacos de náilon e incubadas no rúmen de um bovino macho castrado, mestiço Caracu $\times$ Nelore, com $350 \mathrm{~kg}$ de peso vivo $(\mathrm{PV})$ durante 144 horas. Seqüencialmente, as amostras foram retiradas e processadas segundo metodologia descrita por Berchielli et al. (2000). O material remanescente da incubação foi submetido à análise para determinação dos teores de FDN. Desta forma, a excreção fecal da MS foi calculada pela relação entre o consumo de FDNi (g) e sua respectiva porcentagem nas amostras fecais. Uma vez obtida a excreção fecal da MS, a excreção fecal dos demais nutrientes foi calculada pela multiplicação da excreção fecal de MS pela concentração de nutrientes nas fezes. Assim, o coeficiente
Tabela 3 - Composição química das dietas experimentais

\begin{tabular}{lccccc}
\hline & \multicolumn{5}{c}{ Nível de grão e capim-pé-de-galinha } \\
& \multicolumn{5}{c}{ no concentrado (\%) } \\
\cline { 2 - 6 } Ingrediente & 0 & 16,0 & 32,5 & 48,0 & 67,0 \\
\hline Proteína bruta & 15,20 & 15,16 & 15,31 & 15,08 & 15,26 \\
Extrato etéreo & 2,81 & 2,57 & 2,30 & 2,08 & 1,78 \\
Matéria mineral & 4,01 & 4,13 & 4,28 & 4,36 & 4,53 \\
Matéria orgânica & 92,99 & 92,87 & 92,72 & 92,64 & 92,47 \\
Carboidratos totais & 77,78 & 77,94 & 77,90 & 78,27 & 78,23 \\
FDN & 33,32 & 33,90 & 34,54 & 35,06 & 35,80 \\
FDNI & 14,54 & 15,24 & 15,97 & 16,63 & 17,47 \\
\hline
\end{tabular}

FDN - fibra insolúvel em detergente neutro; FDNi - fibra indigestível em detergente neutro.

de digestibilidade aparente (\%) de MS e dos nutrientes foi obtido pela relação entre o consumo de nutrientes e sua excreção fecal multiplicada por 100 .

O teor de nutrientes digestíveis totais (NDT), em \%, foi calculado pela seguinte equação: NDT $(\%)=\mathrm{PBd}+\mathrm{CTd}+$ $(\mathrm{EEd} * 2,25)$, em que $\mathrm{CTd}=$ carboidratos totais digestíveis; $\mathrm{PBd}=$ proteína bruta digestível; e EEd $=$ extrato etéreo digestível (Brody, 1945).

Os dados de consumo e digestibilidade aparente dos nutrientes foram submetidos a análises de variância e de regressão, segundo os níveis de inclusão de grão do capim-pé-de-galinha na dieta dos animais, utilizando-se o software estatístico SAEG (2001), de acordo com o seguinte modelo, considerando um delineamento inteiramente casualizado:

$$
\mathrm{Y}_{\mathrm{ij}}=\mu+\mathrm{N}_{\mathrm{i}}+\varepsilon_{\mathrm{ij}}
$$

em que: $\mathrm{Y}_{\mathrm{ij}}=$ valor da variável consumo ou digestibilidade referente ao animal i e à dieta $\mathrm{j} ; \mu=$ média geral; $\mathrm{N}_{\mathrm{i}}=$ efeito referente ao n-ésimo nível de inclusão do grão de capim-péde-galinha; e $\varepsilon_{\mathrm{ij}}=$ erro aleatório, pressuposto normal e independentemente distribuído com média zero e variância comum.

\section{Resultados e Discussão}

Não foram observados efeitos $(\mathrm{P}>0,05)$ dos níveis de grão de pé-de-galinha na dieta sobre o consumo dos 
nutrientes avaliados (Tabela 4). O consumo de MS obtido neste estudo foi $73 \%$ inferior ao observado por Souza et al. (2004), de $1.412 \mathrm{~g} /$ animal/dia, ao avaliarem dietas com diversos níveis de casca de café em ovinos com $48 \mathrm{~kg}$ de peso vivo. Entretanto, quando expresso em porcentagem do peso vivo, o valor foi 3,03\%, ligeiramente superior ao verificado por esses autores, o que confirma a importância de se expressar o consumo de diversas formas, ou seja, em termos absolutos e relativos, para que comparações possam ser feitas entre os trabalhos e as variações decorrentes de diferenças de peso dos animais sejam corrigidas.

Ochove et al. (2006), em experimento com ovinos em confinamento, avaliaram dietas à base de cana forrageira e com relação volumoso:concentrado de 60:40 e 40:60 e obtiveram consumos de MS de 3,81 e 4,48\% do PV, respectivamente. Entretanto, o peso vivo dos cordeiros utilizados por esses autores era inferior ao dos utilizados neste estudo.

Os valores de consumo de MS, em porcentagem do PV, obtidos neste trabalho foram próximos aos observados por Ítavo et al. (2006), de 3,39\%; Véras et al (2005), de 3,28\%; Zeuola et al. (2003), de 2,90\%; Rodrigues et al. (2003), de 2,91\%; e Souza et al. (2004), de 3,03\%, ao avaliarem dietas contendo relação volumoso:concentrado de 50:50, 70:30 e 60:40, respectivamente.

O consumo de $\mathrm{PB}$, expresso em relação ao consumo de MS, foi de $14 \%$ e está de acordo com o preconizado pelo NRC (1985) para cordeiros de raças ou grupos genéticos de crescimento moderado, com 20 a $30 \mathrm{~kg}$.

Considerando o consumo de FDN, expresso em $\mathrm{g} / \mathrm{kg}$ de $\mathrm{PV}$, pode-se inferir que não houve efeito de repleção ruminal na regulação do consumo de MS. Mertens (1987) verificou que o consumo é limitado pela repleção ruminal quando a ingestão de FDN varia de 11 a 13 g/ $\mathrm{kg}$ de PV. Assim, a demanda fisiológica dos animais pode ter sido o principal fator regulador do consumo de alimentos, uma vez que as dietas foram formuladas para apresentar relação volumoso:concentrado de 50:50 e os volumosos utilizados apresentaram teores médios de FDN. Além disso, os animais alimentados com concentrado com 100\% de substituição do fubá de milho pelo grão de capim-pé-degalinha apresentaram consumo médio de 11,51 g de FDN consumida por $\mathrm{kg}$ de $\mathrm{PV}$, o que indica a ocorrência de repleção ruminal. Entretanto, considerando que não foi verificada diferença significativa no consumo diário de MS entre as dietas, é possível que o consumo não tenha sido limitado pelos fatores físicos da dieta.

Considerando que a FDN tem forte efeito de distenção ruminal, pode-se inferir que o consumo de MS varia com o nível de concentrado na dieta até o nível que a demanda fisiológica do animal controla o consumo. Bueno et al. (2004) verificaram aumento linear do consumo de MS em cordeiros de $30 \mathrm{~kg}$ de peso vivo quando aumentaram a proporção de concentrado na dieta, cujos valores variaram de 3,27 a 3,66\% do consumo de MS, em porcentagem do PV.

O aumento do grão de pé-de-galinha na dieta reduziu linearmente $(\mathrm{P}<0,05)$ os coeficientes de digestibilidade de MS, carboidratos totais (CT) e NDT (Tabela 5). Cada unidade percentual de grão de capim-pé-de-galinha na dieta reduziu o coeficiente de digestibilidade da MS em $0,1425 \%$, o dos carboidratos totais em $0,1911 \%$ e o NDT em $0,1612 \%$. Esse fato pode ser explicado pelos maiores teores de FDN e de FDNi neste ingrediente, o que, em última análise, afetou a disponibilidade de energia para o animal.

Tabela 4 - Consumo de nutrientes das dietas experimentais (\%)

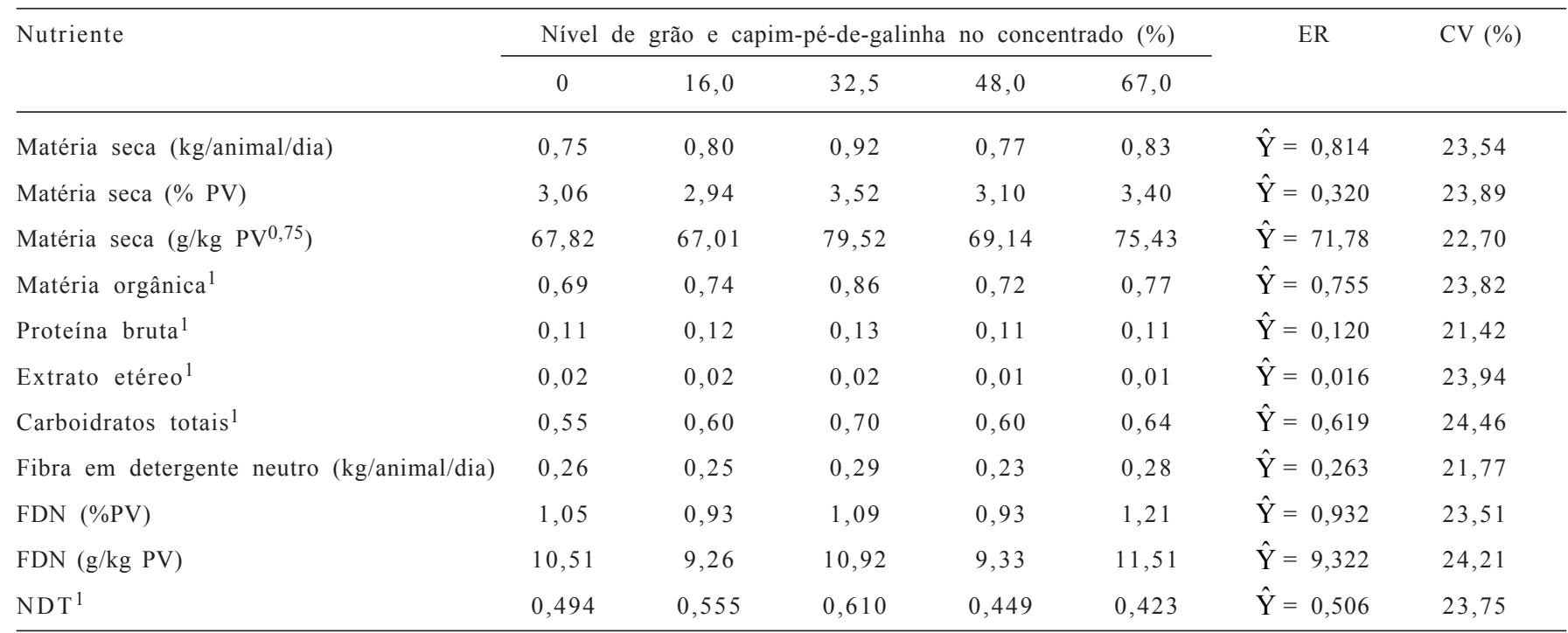


Tabela 5 - Coeficientes (\%) de digestibilidade de nutrientes das dietas

\begin{tabular}{|c|c|c|c|c|c|c|c|c|c|}
\hline \multirow[t]{2}{*}{ Nutriente } & \multicolumn{5}{|c|}{ Nível de grão de capim-pé-de-galinha (\%) } & \multirow[t]{2}{*}{ ER } & \multirow[t]{2}{*}{$\mathrm{CV}(\%)$} & \multirow[t]{2}{*}{$\mathrm{R}^{2}$} & \multirow[t]{2}{*}{$\mathrm{P}$} \\
\hline & 0 & 16,0 & 32,5 & 48,0 & 67,0 & & & & \\
\hline Matéria seca & 61,66 & 57,84 & 63,83 & 56,18 & 50,91 & 1 & 11,25 & 0,55 & 0,0409 \\
\hline Matéria orgânica & 57,48 & 57,75 & 64,69 & 56,64 & 51,71 & 2 & 9,56 & 0,73 & 0,0342 \\
\hline Proteína bruta & 57,37 & 55,00 & 59,78 & 59,59 & 52,74 & 3 & 14,67 & - & - \\
\hline Extrato etéreo & 67,03 & 71,50 & 69,31 & 53,86 & 72,60 & 4 & 23,92 & - & - \\
\hline Carboidratos totais & 63,57 & 58,39 & 65,90 & 47,05 & 53,18 & 5 & 20,75 & 0,43 & 0,1137 \\
\hline Fibra em detergente neutro & 30,91 & 47,73 & 57,09 & 44,26 & 45,71 & 6 & 15,00 & 0,73 & 0,0022 \\
\hline Nutrientes digestíveis totais & 65,82 & 59,43 & 66,20 & 58,28 & 51,01 & 7 & 12,64 & 0,59 & 0,0467 \\
\hline
\end{tabular}

$1 \hat{\mathrm{Y}}=62,72-0,1425 \mathrm{X} ; 2 \hat{\mathrm{Y}}=56,37+0,003638 \mathrm{X}-0,006519 \mathrm{X}^{2} ; 3 \hat{\mathrm{Y}}=56,90 ; 4 \hat{\mathrm{Y}}=66,86 ; 5 \hat{\mathrm{Y}}=63,85-0,1911 \mathrm{X} ; 6 \hat{\mathrm{Y}}=32,69+1,057 \mathrm{X}-0,01336 \mathrm{X}^{2}$ $7 \hat{\mathrm{Y}}=65,83-0,1612 \mathrm{X}$.

A FDN apresenta digestão lenta e incompleta no trato gastrintestinal (Mertens, 1994)e, por esse motivo, espera-se que alimentos ou dietas com maiores percentuais desta fração tenham menor disponibilidade de nutrientes, como o grão do capim-pé-de-galinha, que apresentou 55\% mais FDN que o fubá de milho. Além disso, pelo fato de apresentar 132\% mais FDNi que o fubá de milho, esperava-se menor digestão do grão do capim-de-pé-de-galinha, pois a FDNi apresenta total indisponibilidade no trato gastrintestinal e, desta forma, sua concentração nos alimentos ou nas dietas pode ser inversamente relacionada à digestibilidade (Cabral et al., 2006).

Observou-se efeito quadrático somente para os coeficientes de digestibilidade da matéria orgânica (MO) e FDN. O ponto de máximo do coeficiente de digestibilidade da MO foi de 57,64\% e ocorreu no nível de $42,36 \%$ do grão do capim pé-de-galinha, enquanto o do coeficiente de digestibilidade da FDN foi de $53,60 \%$ e ocorreu no nível de $39,56 \%$ de grão de pé-de-galinha.

Não foram observados efeitos $(\mathrm{P}>0,05)$ do grão de capim-pé-de-galinha nos coeficientes de digestibilidade da PB e do EE. Zeoula et al. (2003), Souza et al. (2004) e Verás et al. (2005) observaram valores médios para o coeficiente de digestibilidade da MS de 65,77; 60,0 e 62,3\%, respectivamente. Ressalta-se que esses autores, com exceção de Souza et al. (2004), trabalharam com a mesma relação volumoso:concentrado empregada neste trabalho.

Henrique et al. (2003), avaliando dietas contendo níveis crescentes de polpa cítrica, com ovinos de $34 \mathrm{~kg}$ de peso vivo, observaram coeficiente de digestibilidade da MS de $72 \%$. A discrepância dos valores verificados por esses autores e os obtidos neste estudo, principalmente quando fornecido o concentrado sem grão de capim-péde-galinha, pode ser atribuída ao elevado nível de concentrado utilizados pelos autores, de $80 \%$. A redução nos coeficientes de digestibilidade de carboidratos totais e
NDT pode afetar o fluxo de proteína microbiana para o intestino delgado dos animais, pois, conforme o NRC (2001), para cada kg de NDT consumido, são produzidos $130 \mathrm{~g}$ de $\mathrm{PB}$ microbiana. Considerando que a maior parte dos nutrientes da dieta é digerida no rúmen e que esta digestão resulta principalmente na produção de proteína microbiana, principal fonte de aminoácidos para mantença e atividades produtivas do animal (Van Soest, 1994; Russel et al., 1992), é possível que a redução dos coeficientes de digestibilidade dos carboidratos totais e do NDT tenha reduzido o fluxo de aminoácidos para o animal.

Da mesma forma, pode-se inferir que a redução do coeficiente de digestibilidade da MS e do teor de NDT decorrente do aumento dos níveis de grão de pé-degalinha na dieta promoveu redução da disponibilidade de energia para o animal e para a microbiota ruminal. Considerando que os carboidratos totais representam a principal fonte de energia aos microrganismos ruminais, provavelmente houve prejuízo ao crescimento da microbiota ruminal e da produção de ácidos graxos voláteis. Assim, pode-se sugerir que o uso do grão de capim-pé-de-galinha seja feito até o nível de $50 \%$ em substituição ao fubá de milho no concentrado para ovinos, que corresponde ao nível de $32,5 \%$ no concentrado, pois quantidades superiores podem promover reduções significativas na digestão dos nutrientes e no desempenho animal. A utilização desse ingrediente não deve ser baseada somente nos custos por tonelada, como praticado pela maioria dos produtores e técnicos para diversos alimentos alternativos. Deve-se proceder à avaliação do custo da tonelada de NDT, em comparação aos alimentos convencionais, como o milho, e a outros alimentos.

Considerando a inexistência de estudos avaliando o grão de capim-pé-de-galinha na alimentação animal, sobretudo na dieta de ovinos, não foi possível a comparação dos resultados obtidos nesta pesquisa com os de outros trabalhos, 
o que torna necessária a realização de mais pesquisas para avaliação do uso desse ingrediente em outros níveis na dieta e em associação a outros volumosos.

\section{Conclusões}

A substituição do fubá de milho por grão do capim-péde-galinha em dietas para ovinos não influenciou o consumo de MS e nutrientes. Todavia, a adição do grão de pé-degalinha reduziu o coeficiente de digestibilidade de MS, MO, CT e nutrientes digestíveis totais da dieta, logo, esse ingrediente pode substituir até $50 \%$ do fubá de milho no concentrado para ovinos.

\section{Literatura Citada}

BERCHIELLI, T.T.; ANDRADE, P.; FURLAN, C.L. Avaliação de indicadores internos em ensaios de digestibilidade. Revista Brasileira de Zootecnia, v.29, n.3, p.830-833, 2000.

BRODY, S. Bioenergetics and growth with special reference to the efficiency complex in domestic animals. New York: Reinhold Publishing Corporation, 1945. 1023p.

BUENO, M.S.; FERRARI JR., E.; POSSENTI, R.A. et al. Desempenho de cordeiros alimentados com silagem de girassol ou de milho com proporções crescentes de ração concentrada. Revista Brasileira de Zootecnia, v.33, n.6, p.1942-1948, 2004.

CABRAL, L.S.; VALADARES FILHO, S.C.; DETMANN, E. et al. Consumo e digestibilidade dos nutrientes em bovinos alimentados com dietas à base e volumosos tropicais. Revista Brasileira e Zootecnia, v.35, n.6, p.2406-2412, 2006.

CRAMPTON, E.W.; DONEFER, E.; LLOYD, L.E. A nutritive value index for forages. Journal of Animal Science, v.19, p.538544,1960

HENRIQUE, W.; SAMPAIO, A.A.M.; LEME, P.R. et al. Digestibilidade e balanço de nitrogênio em ovinos alimentados à base de dietas com elevado teor de concentrado e níveis crescentes de polpa cítrica. Revista Brasileira de Zootecnia, v.32, n.6, p.2007-2015, 2003 (supl. 2).

ÍTAVO, C.C.B.F.; MORAIS, M.G.; ÍTAVO, L.C.V. et al. Efeitos de diferentes fontes de concentrado sobre o consumo e a produção de cordeiros na fase de terminação. Revista Brasileira de Zootecnia, v.35, n.1, p.139-146, 2006.

MERTENS, D.R. Predicting intake and digestibility using mathematical models of ruminal function. Journal of Animal Science, v.64, n.5, p.1548-1558, 1987.
MERTENS, D.R. Regulation of forage intake. In: FAHEY, JR, G.C (Ed.) Forage quality, evaluation and utilization. Winsconsin: American Society of Agronomy, 1994. p.450-493.

NATIONAL RESEARCH COUNCIL - NRC. Nutrient requeriments of sheep. 6.rev.ed. Washington, D.C.: National Academy Press, 1985. $112 \mathrm{p}$

NATIONAL RESEARCH COUNCIL - NRC. Nutrients requirements of dairy cattle. 7.ed. Washington, D.C.: National Academy Press, 2001. $381 \mathrm{p}$.

OCHOVE, V.C.C.; CABRAL, L.S.; JESUS, L.F. et al. Desempenho de ovinos em confinamento alimentados com dietas à base de cana forrageira. In: REUNIÃO SOCIEDADE BRASILEIRA DE ZOOTECNIA, 43., 2006, João Pessoa. Anais... Reunião Anual da Sociedade Brasileira de Zootecnia. (CD-ROM).

REID, J.T. Problems of feed evaluation related to feeding dairy cows. Journal of Dairy Science, v.11, p.2122-2133, 1961.

RODRIGUES, M.M.; NEIVA, J.N.M.; VASCOLCELOS, V.R. et al. Utilização do farelo de castanha de caju na terminação de ovinos em confinamento. Revista Brasileira de Zootecnia, v.32, n.1, p.240-248, 2003.

RUSSELL, J.B.; O'CONNOR, J.D.; FOX, D.G. et al. A net carbohydrate and protein system for evaluation cattle diets: ruminal fermentation. Journal of Animal Science, v.70, n.12, p.3551$3581,1992$.

UNIVERSIDADE FEDERAL DE VIÇOSA - UFV. SAEG - Sistema de análises estatísticas e genéticas. Viçosa, MG: UFV, 2001. (CD-ROM)

SANTOS, R. A criação da cabra e da ovelha no Brasil. Uberaba: Editora Agropecuária Tropical, 2004. 480p.

SILVA, D.J.; QUEIROZ, A.C. Análise de alimentos: métodos químicos e biológicos. 3.ed. Viçosa, MG: Editora UFV, 2004. 235p.

SNIFFEN, C.J.; O'CONNOR, D.J.; Van SOEST, P.J. et al. A net carbohydrate and protein system for evaluating cattle diets: carbohydrate and protein availability. Journal of Animal Science, v.70, n.12, p.3562-3577, 1992.

SOUZA, A.L.; GARCIA, R.; BERNARDINO, F.S. et al. Casca de café em dietas de carneiros: consumo e digestibilidade. Revista Brasileira de Zootecnia, v.33, n.6, p.2170-2176, 2004 (supl. 2).

Van SOEST, P.J.; ROBERTSON, J.B.; LEWIS, B.A. Methods for dietary fiber, neutral detergent fiber, and nonstarch polyssacarides in relation to animal nutrition. Journal of Dairy Science, v.74, n.10, p.3583-3597, 1991

Van SOEST, P.J. Nutritional ecology of the ruminant. 2.ed Ithaca: Cornell University Press, 1994. 476p.

VÉRAS, R.M.L.; FERREIRA, M.A.; VÉRAS, A.S.C. et al. Substituição do milho por farelo de palma forrageira em dietas para ovinos em crescimento: consumo e digestibilidade. Revista Brasileira de Zootecnia, v.34, n.1, p.351-356, 2005

ZEOULA, L.M.; CALDAS NETO, S.F.; GERON, L.J.V. et al. Substituição do milho pela farinha de varredura de mandioca (Manihot esculenta Crantz) em rações de ovinos: consumo, digestibilidade, balanços de nitrogênio e energia e parâmetros ruminais. Revista Brasileira Zootecnia, v.32, n.2, p.491-502, 2003. 